\title{
Liposuction infiltration: The Quito formula - a new approach based on an old concept
}

\author{
Iván Marcelo Cueva Galárraga MD
}

IM Cueva Galárraga. Liposuction infiltration: The Quito formula - a new approach based on an old concept. Can J Plast Surg 2011;19(1):17-21.

INTRODUCTION: Liposuction is a highly sought after surgical procedure. Despite its popularity, not all of the factors associated with its execution are well understood. No well-established guidelines exist for plastic surgeons regarding the subcutaneous infiltration of fluid and, thus, the procedure is often performed subjectively.

OBJECTIVE: To establish the usefulness of the Quito formula (infiltrate volume $=$ weight $[\mathrm{kg}] \times$ percentage of body surface to be liposuctioned $\times$ $2.4[\mathrm{~mL}])$ for calculating the volume of fluid to be infiltrated subcutaneously during small-volume liposuction performed under epidural anesthesia.

METHODS: A prospective study was conducted on a group of 50 patients who were candidates for liposuction on multiple body parts between November 2004 and February 2010.

RESULTS: The maximum volume of infiltrate was $5000 \mathrm{~mL}$ and the maximum volume of aspirate was $4500 \mathrm{~mL}$, with a 30\% total aspirated area. No patient required blood transfusion, and there were no major complications. However, one patient presented with a small local infection, another with a sacral seroma and two patients had postdural puncture headaches. No patient showed clinical signs consistent with overhydration, dehydration, pulmonary embolism, fat embolism or lidocaine intoxication.

CONCLUSIONS: When performing small-volume liposuction, subcutaneous infiltration using the Quito formula to calculate the volume of infiltrate proved to be useful, safe and objective.

Key Words: Infiltration; Liposuction; Quito formula; Small volume

\section{L'infiltration pour la liposuccion : la formule} Quito - une nouvelle démarche fondée sur un vieux concept

INTRODUCTION : La liposuccion est une intervention chirurgicale très recherchée. Malgré sa popularité, les facteurs associés à son exposition ne sont pas tous bien compris. Il n'existe aucune directive bien établie à l'intention des plasticiens au sujet des infiltrations sous-cutanées de liquide et, par conséquent, l'intervention est souvent exécutée de manière subjective.

OBJECTIF : Établir l'utilité de la formule Quito (volume d'infiltrat = poids $[\mathrm{kg}] \times$ pourcentage de surface corporelle devant faire l'objet de la liposuccion $\times 2,4[\mathrm{~mL}]$ ) pour calculer le volume de liquide à infiltrer par voie sous-cutanée pendant une liposuccion à faible volume exécutée sous anesthésie péridurale.

MÉTHODOLOGIE : Les chercheurs ont mené une étude prospective auprès d'un groupe de 50 patients candidats à la liposuccion sur de multiples parties du corps entre novembre 2004 et février 2010.

RÉSULTATS : Le volume maximal d'infiltrat était de $5000 \mathrm{~mL}$, et le volume maximal d'aspirat, de $4500 \mathrm{~mL}$, pour une région aspirée totale de $30 \%$. Aucun patient n'a dû recevoir de transfusion sanguine, et on n'a constaté aucunes complications majeures. Cependant, un patient a souffert d'une petite infection localisée, un autre, d'un sérome de la région sacrée et deux, de céphalées post-ponction durale. Aucun patient n'a démontré de signes cliniques évocateurs de surhydratation, de déshydratation, d'embolie pulmonaire, d'embolie graisseuse ou d'intoxication à la lidocaïne.

CONCLUSIONS : Pour effectuer une liposuccion à faible volume, l'infiltration sous-cutanée faisant appel à la formule Quito afin de calculer le volume d'infiltrat s'est révélée utile, sécuritaire et objective.

total aspirate (total fat and fluid) in a single session, especially when it relates to outpatient surgeries.

Large-volume liposuction is defined as a single operation in which the volume aspirated is greater than $5000 \mathrm{~mL}(8,9)$.

This recommendation means that for any given patient, regardless of their weight, no more than $5000 \mathrm{~mL}$ should be aspirated. This limit must be interpreted with caution because extracting this amount from a thin patient will not have the same effect as extracting it from an obese patient. In small-volume liposuction, the aspirated volume does not reach $5000 \mathrm{~mL}$.

Despite these recommendations, there are reports in the literature of studies $(10,11)$ on large-volume liposuction performed with a high margin of safety.

For several reasons, the majority of plastic surgeons believe that performing small-volume liposuctions is safer; hence, large-volume liposuctions are not very common, at least not presently (12).

Techniques for infiltration during liposuction

To our knowledge, there are two existing techniques for subcutaneous fluid infiltration: the super-wet (13) and the tumescent $(14,15)$.

The super-wet technique infiltrates $1 \mathrm{~mL}$ of solution for $1 \mathrm{~mL}$ of aspirated volume. The tumescent technique infiltrates $3 \mathrm{~mL}$ to $4 \mathrm{~mL}$ of 
solution for each millilitre of aspirated volume. Many studies have shown no significant differences between these two techniques in terms of bleeding, pain control, fluid management, esthetic results or complications. In studies that mention using the tumescent technique for large-volume liposuction, the aspirated volumes are frequently found to be equivalent to those of small-volume liposuction (16). However, there seems to be a tendency to use the super-wet technique.

\section{Physiological aspects of fluids and body compartments}

It has been estimated that $20 \%$ of the fluid infiltrated subcutaneously remains in the intravascular space and $80 \%$ enters the slightly overhydrated interstitial space (17). Between $50 \%$ and $70 \%$ of the volume infiltrated subcutaneously reaches the intravascular space in the immediate postoperative period (18). The subcutaneous infiltration solution is absorbed into the intravascular space over a period of $48 \mathrm{~h}$, especially at the end of the procedure when the surgical wounds are sutured (19).

When a crystalloid fluid, such as $0.9 \%$ sodium chloride (saline) or lactated Ringer's solution, is infused intravenously, only $20 \%$ of its volume remains in the intravascular space (20). In either case, this volume of infiltrate should not be a problem clinically because the patients who undergo liposuction are typically young, American Society of Anesthesiology classification I or II, and theoretically able to tolerate this load.

These considerations would argue in favour of tumescent liposuction because it eliminates the necessity of administering intravenous fluids during or after the procedure $(21,22)$. One must rely on the compensatory thirst mechanism (which should be intact for all patients) and his/her renal and cardiovascular function to compensate for any deficit or excess. Evidently, there is nothing better than the surgeon using good clinical reasoning to assess parameters such as diuresis, blood pressure, heart rate and respiratory rate.

\section{Fluid intake during the preoperative, transoperative and postoperative periods}

The patient arrives in the operating room after several hours of fasting, and the anesthesiologist begins fluid replacement in the preoperative period (23). If general anesthesia is administered to perform largevolume liposuction, the surgeon is more comfortable performing more extensive and combined procedures (24). It is important to remember, however, that more involved procedures imply many types of changes other than simply the hemodynamic ones (25-27).

By contrast, liposuction performed under epidural anesthesia establishes a variable hypotension that must be compensated for with crystalloids for the duration of the procedure $(28,29)$. The published hydration schemes are related to large-volume liposuctions and vary in how they achieve safe management of fluids, which is one of the most important perioperative aspects (30). Some studies (31-33) report that liposuction behaves like a burn, although not to the point of causing the profound organic changes that are well known in patients who suffer that type of thermal trauma.

These factors must be considered to better understand how to manage fluid intake in these patients; for example, hypodermoclysis is an accepted form of hydration in patients who cannot be hydrated intravenously. Thus, the plastic surgeon plays a role in providing part of the fluid to patients undergoing liposuction (34-36).

Despite its importance, subcutaneous infiltration in liposuction procedures is often evaluated in a subjective manner.

\section{Patient evaluation}

All patients were assessed by laboratory examinations including hematology, coagulation times, blood chemistry and urine analysis. They also underwent a cardiac evaluation with an electrocardiogram. A chest radiograph was taken, if necessary.

\section{Medication}

Each patient received $1 \mathrm{~g}$ of cefazolin shortly after the epidural, receiving a total of three doses during hospitalization. In addition, they were given a total of $12 \mathrm{mg}$ of dexamethasone ( $4 \mathrm{mg}$ before the procedure, $4 \mathrm{mg}$ at the end of the operation and $4 \mathrm{mg}$ at $24 \mathrm{~h}$ ). For pain control, a combination of acetaminophen and ibuprofen was administered, and they received ciprofloxacin orally for seven days.

\section{Infiltrate solution}

The infiltrate solution was prepared as follows and heated to $38^{\circ} \mathrm{C}$ :

- Lactated Ringer's solution, $1000 \mathrm{~mL}$.

- 1:1000 adrenaline, $1 \mathrm{~mL}$.

- $8.4 \%$ sodium bicarbonate, $5 \mathrm{~mL}$.

- $2 \%$ lidocaine, $8 \mathrm{~mL}$.

Sodium chloride solution $(0.9 \%)$ was occasionally used, without any problems, as an alternative to lactated Ringer's solution.

The solution was prepared in this way to mainly inhibit bacterial growth, control pain and achieve hemostasis $(37,38)$.

\section{Patient preparation and surgical technique}

Liposuction was performed from the deeper layers to the surface using a radial technique. The procedure always began with the patient in the ventral decubitus position and then in the dorsal decubitus position.

General anesthesia was not administered to any patients; all of the procedures were performed under epidural anesthesia. Performance of blood transfusions was not necessary; drains were not placed in any of the patients.

Seventy per cent of the patients underwent gluteal lipoinjection. At the end of the procedure, the skin of the patient was covered with sterile dressings, which were secured with elastic bandages. Approximately four days after the procedure and after the cessation of fluid leakage from the incision sites, a postsurgical compression garment was worn for at least one month.

The patients were advised to undergo an external ultrasound and massage (lymphatic drainage) sessions eight days after the procedure.

Despite the comments about super-wet liposuction, it is not always possible to infiltrate $1 \mathrm{~mL}$ of fluid and aspirate $1 \mathrm{~mL}$, and should not be considered a goal. It is always important to do no harm to the patient and to provide an aesthetic result that meets the expectations of both the surgeon and the patient $(39,40)$.

Always infiltrating $5000 \mathrm{~mL}$ and aspirating $5000 \mathrm{~mL}$ does not account for the fact that part of the infiltrate enters different body compartments, as previously mentioned. Surgeons should wait at least $20 \mathrm{~min}$ before beginning liposuction; it is reasonable to assume that there is movement of fluids from one compartment to another during this time.

Using the Quito formula eliminates the need for invasive monitoring of heart rate, pulmonary artery wedge and central venous pressures, as has been reported in other types of liposuction (41).

Using this formula, surgeons can operate on patients with an adequate safety margin, even if the supply of preoperative and perioperative fluids is excessive, as apparently has been, and still is, common (4).

For all of these reasons, a more reliable management scheme is needed to perform these types of procedures safely.

\section{The Quito formula

$$
\begin{aligned}
\text { Infiltrate volume } & =\text { Weight }(\mathrm{kg}) \times \text { percentage of body surface } \\
& \text { for liposuction } \times 2.4(\mathrm{~mL})
\end{aligned}
$$

\section{METHODS}

Based on these considerations, this formula was used when performing small-volume liposuctions under epidural anesthesia, given the benefits of this anesthetic technique (42).

Similar to the formulas for the hydration of burn patients, this formula uses a fixed value ( $2.4 \mathrm{~mL}$ of crystalloid solution), the weight of the patient in kilograms and the percentage of body surface to be liposuctioned (calculated according to Table 1 or using a worksheet). It yields a value in millilitres that indicates the volume of infiltrate to be administered; therefore, it needs to be as accurate as possible. 


\begin{tabular}{|c|c|c|c|c|}
\hline Areas to be liposuctioned & Body surface, \% & Total body surface for liposuction, \% & $\begin{array}{c}\text { Constant } \\
\text { volume, } \\
\mathrm{mL}\end{array}$ & $\begin{array}{l}\text { Approximation of the total } \\
\text { volume }(\mathrm{mL}) \text { to infiltrate } \\
\text { subcutaneously for each area }\end{array}$ \\
\hline Neck & 1 & 1 & 2.4 & 168 \\
\hline Breast, each one & 2.5 & - & 2.4 & - \\
\hline Arm, each one & 2 & 4 & 2.4 & $336+336=672$ \\
\hline Upper abdomen & 4.5 & 4.5 & 2.4 & 756 \\
\hline Lower abdomen & 4.5 & 4.5 & 2.4 & 756 \\
\hline Flank/hip, each one & 4 & 8 & 2.4 & $672+672=1344$ \\
\hline Upper back & 4 & 4 & 2.4 & 672 \\
\hline Lower back & 4 & 4 & 2.4 & 672 \\
\hline Buttock, each one & 3 & - & 2.4 & - \\
\hline Inner thigh, each one & 2 & - & 2.4 & - \\
\hline Anterior thigh, each one & 2 & - & 2.4 & - \\
\hline Lateral thigh, each one & 2 & - & 2.4 & - \\
\hline Back thigh, each one & 2 & - & 2.4 & - \\
\hline Knee, each one & 1 & - & 2.4 & - \\
\hline Leg, each one & 6 & - & 2.4 & - \\
\hline \multicolumn{5}{|l|}{ Weight: 70 kg } \\
\hline $\begin{array}{l}\text { Total percentage of body surface for } \\
\text { liposuction }\end{array}$ & 71 & 30 & & \\
\hline Volume of solution to infiltrate, $\mathrm{mL}^{*}$ & & & & 5040 \\
\hline
\end{tabular}

*Volume of solution to infiltrate $=$ weight $(\mathrm{kg}) \times$ percentage of body surface for liposuction $\times 2.4(\mathrm{~mL})$

\section{TABLE 2}

Simulation using the Quito formula - fluid management

\begin{tabular}{|c|c|c|}
\hline Input & & Output \\
\hline Infiltrated fluid: 5040 mL & & Fat + fluid aspirated: $3000 \mathrm{~mL}$ \\
\hline $\begin{array}{l}\text { Preoperative and postoperative intravenous fluids: } \\
5000 \mathrm{~mL} \text { over } 24 \mathrm{~h}\end{array}$ & & Diuresis: $2500 \mathrm{~mL}$ over $24 \mathrm{~h}$ \\
\hline Fluids taken orally: $800 \mathrm{~mL}$ over $24 \mathrm{~h}$ & & Drainage through liposuction (unsutured wounds): $1500 \mathrm{~mL}$ over $24 \mathrm{~h}$ \\
\hline \multirow[t]{3}{*}{ Total administered: $10,840 \mathrm{~mL}$ over $24 \mathrm{~h}$} & & Total eliminated: $7000 \mathrm{~mL}$ over $24 \mathrm{~h}$ \\
\hline & Positive balance: $3840 \mathrm{~mL}$ & \\
\hline & $3840 \mathrm{~mL} / 70 \mathrm{~kg}=54.85 \mathrm{~mL} / \mathrm{kg}$ & \\
\hline
\end{tabular}

Example: Simulated calculations for an average patient

Consider the liposuction of a female patient weighing $70 \mathrm{~kg}$ with an American Society of Anesthesiology classification I. The areas to be liposuctioned are the neck, arms, upper and lower abdomen, hips, upper and lower back (Tables 1 and 2).

Calculation: $70 \mathrm{~kg} \times 2.4 \mathrm{~mL} \times 30 \%$ of body surface for liposuction $=$ $5040 \mathrm{~mL}$ for subcutaneous infiltration.

Once the value for the volume of infiltrate is obtained, this volume will be distributed in each anatomical area according to the characteristics of the patient.

A detailed table for estimating the body surface to be liposuctioned that applies to the preceding example is provided above (Table 1).

Thus, a somewhat more appropriate and physiological calculation of the volume that will be administered subcutaneously can be performed to increase the objectivity of this element of the liposuction procedure. This volume $(54.85 \mathrm{~mL} / \mathrm{kg})$ is smaller than those previously published; it has been stated that a final residual fluid volume of between $90 \mathrm{~mL} / \mathrm{kg}$ and $120 \mathrm{~mL} / \mathrm{kg}$ is easily tolerated by a healthy patient (43).

The preoperative and postoperative fluid supply could be increased, if necessary, without causing major problems.

Suturing wounds is not recommended because the ecchymosis will be notorious and will also cause discomfort to the patients; however, this causes a greater loss of fluid from the subcutaneous space. This loss causes a deficit in the fluid balance and makes it necessary to administer extra fluids intravenously, as well as orally, to compensate.
According to Table 1, the maximum body surface for liposuction is $71 \%$, but procedures actually reaching this limit are neither recommended nor have been performed.

For safety reasons, the present article does not propose exceeding $30 \%$ of the body surface in a single liposuction session (44-46).

According to the formula, to liposuction the maximum body surface of $71 \%$ of a $70 \mathrm{~kg}$ patient, $11,928 \mathrm{~mL}$ of fluid would need to be infiltrated, which would classify it as a large-volume liposuction. In fact, this formula may also be useful for calculating the volume of infiltrate for this type of liposuction.

If the patient requires liposuction in which the volume of infiltrate greatly exceeds $5000 \mathrm{~mL}$, one or more additional procedures are advised until the desired result is obtained. When the patients understand the magnitude of the operation and the potential risks associated, they almost always accept this alternative.

As seen in the example, in practice, the amount aspirated is consistent with the recommendation from the American Society of Plastic Surgeons for outpatient procedures (47). This conclusion assumes that for $1 \mathrm{~mL}$ of solution infiltrated, $1 \mathrm{~mL}$ of fat is aspirated. The average dose of lidocaine used was $11.42 \mathrm{mg} / \mathrm{kg}$ of body weight; the average dose of adrenaline was never greater than $0.07 \mathrm{mg} / \mathrm{kg}$ of body weight.

\section{RESULTS}

The Quito formula was successfully used in a group of 50 women and two men who underwent liposuction between November 2004 and 
February 2010. One patient had a seroma in the sacral area that required several aspirations until it was resolved, and another patient had approximately $6 \mathrm{~cm}$ area of cellulitis in the right outer thigh that was treated with oral antibiotics. Two patients experienced postdural puncture headaches that were resolved with analgesics, hydration and rest.

No patient showed clinical data compatible with overhydration, dehydration, pulmonary embolism, fat embolism or lidocaine intoxication.

The presented formula has also been used to perform abdominoplasty plus liposuction, but these patients were not discussed in the present article.

Once the operation was completed, $80 \%$ of the patients were discharged after a $24 \mathrm{~h}$ observation period; the other $20 \%$ remained in the clinic for at least an additional $12 \mathrm{~h}$.

If desired, and if the liposuction area is small, liposuction can be performed under local anesthesia following these parameters with alterations in the infiltrate solution, particularly with regard to the concentration of lidocaine and sodium bicarbonate.

\section{DISCUSSION}

Liposuction is a complex procedure in every respect. The trauma induced in a patient undergoing this procedure is not trivial, and a plastic surgeon must consider a series of factors to achieve an ideal result that will often be judged solely from an esthetic point of view.

To perform this type of procedure, all of the associated factors related to the patient must be taken into account if their surgical experience is to be as comfortable as possible.

There have been many advances in the preoperative, perioperative and postoperative management of patients, in addition to breakthroughs in anesthesia, pain control, pulmonary embolism prevention and the use of new liposuction technologies. However, the factors for which the surgeon is totally responsible, such as the amount, concentration and type of solution for the infiltrate, cannot be neglected.

It is not uncommon for plastic surgeons to resort to tables, measurements, formulas, and rates or volumes to perform calculations that assist in the treatment of patients $(48,49)$.

Liposuction should not be exempt from this kind of approach. Any effort made by surgeons and their teams will be worthwhile if, in the end, the patient feels safe and is happy with the results.

I have tried to find a way to use an existing formula to calculate the appropriate amount of infiltrate for a liposuction procedure.

Although the number of patients in the present study was small, the results are encouraging and will hopefully be useful to surgeons who do not perform large-volume liposuctions, who work alone or in a group, and who do not know the safe amount of infiltrate for a liposuction procedure.

The Quito formula is only an estimation tool or guide. It is not similar to the Lund-Browder chart, the Parkland formula or the Modified Brooke formula, which are used in the treatment of burn patients; although, the basic principles are similar (50).

It must be emphasized that the treatment of patients undergoing liposuction is not the same as the treatment of burn patients.

Without resorting to a printed template, these values can be easily calculated using a desktop computer, a laptop or personal digital assistant using Microsoft Excel spreadsheets (Microsoft Corporation, USA) that can be saved under the medical histories of each patient. This type of spreadsheet is also suitable for determining the doses of adrenaline and lidocaine.

The management of all the factors involved in this procedure, not only fluids, must be based on sound clinical and surgical judgment exercised by surgeons and their teams, always evaluating the characteristics of each patient $(51,52)$.

It is important not to confuse several important facts that, despite being intimately related, are not the same; specifically, the infiltration of crystalloid solutions for liposuction and the maintenance and replenishment of fluids intravenously during the course of and after surgery. These calculations take into account, among other variables, the amount of fluid and fat aspirated, bleeding and the clinical condition of each patient.

It is worth remembering Grazer and Meister's (53) point of view regarding the safety of liposuction surgery, which does not take into account some of the abovementioned factors: "As I view it, the current death rate is a culmination of physician one-upmanship, ie, competitive increases in doses of lidocaine to levels surpassing $55 \mathrm{mg} / \mathrm{kg}$ and high-volume suction, or who can take out the most without killing the patient".

In experienced hands, large-volume liposuction is a safe procedure; therefore, it should not be condemned (54-58).

Thus, I believe that we can understand liposuction in a more physiological manner. I also believe that this approach to performing liposuction is clinically and surgically useful.

ACKNOWLEDGEMENTS: The author thanks Dr Tania Morales for her support.

NOTE: The current work was presented in part at the 35th International Annual Symposium of Plastic Surgery - Aesthetics on November 4 to 8, 2008, in Puerto Vallarta, Jalisco, Mexico.

9. Hanke W, Cox SE, Kuznets N, Coleman WP. Tumescent liposuction report performance measurement initiative: National survey results. Dermatol Surg 2004;30:967-78.

10. Cárdenas-Camarena L, González LE. Large-volume liposuction and extensive abdominoplasty: A feasible alternative for improving body shape. Plast Reconstr Surg 1998;102:1698-707.

11. Albin R, de Campo T. Large-volume liposuction in 181 patients. Aesth Plast Surg 1999;23:5-15.

12. Fodor PB. Wetting solutions in aspirative lipoplasty: A plea for safety in liposuction. Aesth Plast Surg 1995;19:379-80.

13. Fodor PB. Defining wetting solutions in lipoplasty. Plast Reconstr Surg 1999;103:1519-20.

14. Klein JA. Anesthetic formulation of tumescent solutions. Dermatol Clin 1999;17:751-9.

15. Klein JA. Tumescent technique for local anesthesia improves safety in large-volume liposuction. Plast Reconstr Surg 1993;92:1085-98.

16. Klein JA. The role of subcutaneous infiltration in suction-assisted lipoplasty: A review. Plast Reconstr Surg 1998;102:2516-8.

17. Rohrich RJ, Beran SJ, Fodor PB. The role of subcutaneous infiltration in suction-assisted lipoplasty: A review. Plast Reconstr Surg 1997;99:514-9. 
18. Commons GW, Halperin BD. Considerations in large-volume liposuction. Sem Plast Surg 2002;16:143-52.

19. Grocott MP, Mythen MG, Gan TJ. Perioperative fluid management and clinical outcomes in adults. Anesth Analg 2005;100:1093-106.

20. Klein JA. The tumescent technique for lipo-suction surgery. Am J Cosmet Surg 1987;4:263-7.

21. Klein JA. Tumescent technique for regional anesthesia permits lidocaine doses of $35 \mathrm{mg} / \mathrm{kg}$ for liposuction. Dermatol Surg Oncol 1990;16:248-63.

22. Pitman GH, Aker JS, Tripp ZD. Tumescent liposuction. Clin Plast Surg 1996;23:633-45.

23. Holte K, Jensen P, Kehlet H. Physiologic effects of intravenous fluid administration in healthy volunteers. Anesth Analog 2003:96:1504-9.

24. Hoefflin SM, Bornstein JB, Gordon M. General anesthesia in an office-based plastic surgical facility: A report on more than 23,000 consecutive office-based procedures under general anesthesia with no significant anesthetic complications. Plast Reconstr Surg 2001;107:243-51.

25. Burk R, Guzman-Stein G, Vasconez L. Lidocaine and epinephrine levels in tumescent technique liposuction. Plast Reconstr Surg 1996;97:1379-84.

26. Gilliland MD, Coates N. Tumescent liposuction complicated by pulmonary edema. Plast Reconstr Surg 1997;99:215-9.

27. Kenkel JM, Lipschitz AH, Luby M, et al. Homodynamic physiology and thermoregulation in liposuction. Plast Reconstr Surg 2004;114:503-13.

28. Knize D, Royce F. Use of preoperative subcutaneous "wetting solution" and epidural block anesthesia for liposuction in the office-based surgical suite. Plast Reconstr Surg 1997;100:1867-74.

29. Teimourian B, Medhi A. Liposuction with standing technique: The true lipo "sculpture". Plast Reconstr Surg 1999;104:1551-2.

30. Pitman GH. The role of subcutaneous infiltration in suction-assisted lipoplasty: A review. Plast Reconstr Surg 1997;99:523-6.

31. Gargan TJ, Courtis EH. The risks of suction lipectomy. Clin Plast Surg 1984;11:457-63.

32. Singer R. Practice advisory on liposuction. Plast Reconstr Surg 2004;113:1491-3.

33. Courtis EH, Choucair RJ, Doneland MB. Large-volume suction lipectomy: An analysis of 108 patients. Plast Reconstr Surg 1992;89:1068-82.

34. Sasson M, Shvartzman P. Hypodermoclysis: An alternative infusion technique. Am Fam Physician 2001;64:1575-8.

35. Slesak G, Schnurle JW, Kinzel E, Jacob J, Dietz K. Comparison of subcutaneous and intravenous rehydration in geriatric patients: A randomized trial. J Am Geriatr Soc 2003;51:155-60.

36. Walsh G. Hypodermoclysis. J Inf Nursing 2005;28:123-9.

37. Craig SB, Concannon MJ, McDonald GA, Puckett CL. The antibacterial effects of tumescent liposuction fluid. Plast Reconstr Surg 1999;103:666-70.
38. Thompson KD, Welykyj S, Massa MC. Antibacterial activity of lidocaine in combination with a bicarbonate buffer. J Dermatol Surg Oncol 1993;19:216-20.

39. Fodor PB. Reflections on lipoplasty: History and personal experience. Aesthetic Surg J 2009;29:226-31.

40. Fodor PB. Lipoplasty - another plea for safety! Aesthetic Plast Surg 1998;22:399-400

41. Kenkel JM, Lipschitz AH, Luby M, et al. Hemodynamic physiology and thermoregulation in liposuction. Plast Reconstr Surg 2004;114:503-13.

42. Moraca RJ, Sheldon DG, Thirlby RC. The role of epidural anesthesia and analgesia in surgical practice. Ann Surg 2003;238:663-73.

43. Commons GW, Halperin B, Chang CC. Large-volume liposuction; a review of 631 consecutive cases over 12 years. Plast Reconstr Surg 2001;108:1753-63.

44. Illouz YG. Liposuction: My current technique. Oper Tech Plast Reconstr Surg 2002;8:12-22.

45. Warwick LG. Propuesta de Recomendaciones de Seguridad: Máximo volumen de grasa extraíble por lipoaspiración con tumefacción. Int J Cosm Med Surg 2005;7:31-6.

46. Cantarelli J, Godoy MF. Safe limits for aspirate volume under wet liposuction. Obes Surg 2009;19:1642-5.

47. Haeck PC, Swanson JA, Gutowski KA, et al; ASPS Patient Safety Committee. Evidence-based patient safety advisory: Liposuction. Plast Reconstr Surg 2009;124(Suppl):28S.

48. Brauman D. Lipoplasty: A case for low-volume procedure. Aesth Surg J 2000;20:373-9.

49. Lund CC, Browder NC. The estimation of areas of burns. Surg Gynecol Obst 1944;79:352.

50. Baxter CR. Fluid and electrolyte changes of the early postburn period. Clin Plast Surg 1974;1:693.

51. Hughes C. Reduction of lipoplasty risks and mortality: An ASAPS survey. Aesth Surg J 2001;21:120-7.

52. Rohrich RJ, Beran SJ. Is liposuction safe? Plast Reconstr Surg 1999;104:819-22.

53. Grazer FM, Meister FL. Complications of the tumescent formula for liposuction. Plast Reconstr Surg 1997;100:1893-6.

54. Trott SA, Beran SJ, Rohrich RJ, Kenkel JM, Adams WP Jr, Klein KW. Safety considerations and fluid resuscitation in liposuction: An analysis of 53 consecutive patients. Plast Reconstr Surg 1998;102:2220-9.

55. Rohrich RJ, Kenkel MK, Janis JE, Beran SJ, Fodor PB. An update on the role of subcutaneous infiltration in suction-assisted lipoplasty. Plast Reconstr Surgery 2002;111:926-7.

56. Cárdenas-Camarena L. Aesthetic surgery of the thoracoabdominal area combining abdominoplasty and circumferential lipoplasty: 7 years' experience. Plast Reconstr Surg 2005;116:881-92.

57. Cárdenas-Camarena L. Lipoaspiration and its complications: A safe operation. Plast Reconstr Surg 2003;112:1435-41.

58. Phillips J, Kenkel J. Updates and advances in liposuction. Aesth Surg J 2010;30:83-97. 